\title{
Antibacterial Activity of Leaves and Rhizome of Curcuma xanthorrhiza Essential Oils on Different Distillation Time
}

\author{
Authors \\ Nur Syafiqah Nadiah Mohammad Rafi ${ }^{1}$, Irmanida Batubara ${ }^{2,3^{*}}$, Anthony Nyangson Steven ${ }^{1}$ \\ Affiliation
${ }^{1}$ Department of Chemistry, Faculty of Science, Universiti Teknologi Malaysia, Malaysia
${ }^{2}$ Tropical Biopharmaca Research Center, Institut Pertanian Bogor, Indonesia
${ }^{3}$ Department of Chemistry, Faculty of Science and Mathematics, Institut Pertanian Bogor, \\ Indonesia
}

\section{Keyword \\ - Curcuma xanthorrhiza \\ $\rightarrow$ Essential Oils \\ $\rightarrow$ Leaves \\ $\rightarrow$ Rhizome}

Received 28 September 2018 Revised 23 October 2018 Accepted 26 November 2018

* Corresponding author Irmanida Batubara Jalan Tanjung Kampus IPB, Dramaga, Babakan, Dramaga, Bogor, Jawa Barat 16680 Email: ime@apps.ipb.ac.id

\section{ABSTRACT}

This research aims to determine the antibacterial activity of Curcuma xanthorrhiza leaves and rhizomes essential oil with different distillation time of 2 hours, 4 hours and 6 hours against Escherichia coli and Staphylococcus aureus. The essential oils produced then separated by thin layer chromatography (TLC) with $n$-hexane: toluene: dichloromethane 1:8:1 as the mobile phase. The result shows that on the first two hours distillation gave the highest yield compared to the next two hours or four hours. Based on TLC chromatograms, the highest content of compounds found at 4-6 hours distillation time. TLC bioautography contact was used for antibacterial activity tested on chromatogram and the clear zone appears on it indicates the spots were active as antibacterial activity against both bacteria with Rf values of 0.35 and 0.49 for rhizomes, rhizome essential oils 4-6 hours distillation time as the most significance active.

\section{INTRODUCTION}

Temulawak (Curcuma xanthorrhiza) comes from Zingiberaceae (ginger) family, kind of herb plants that are very beneficial as traditional medicine. It has known to be used to cure several diseases such as high-cholesterol level, arthritis, heart and liver diseases, constipation and also effective as antioxidants and antibacterial (Kalor and Atun 2017). This plant originated from Indonesia but can be found also in some other Asia countries. The presence of curcuminoids in rhizomes causes the substances having yellow or orange color.

Rhizome is the most used part from temulawak. The rhizome of temulawak was reported has activity as antioxidant, anti-lipidemic, antibacterial, anti-fungi, and antiinflammation (Ozaki 1990, Yasni et al. 1994, Rukayadi et al. 2007, Sylvester et al. 2015). Its rhizomes of $C$. xanthorrhiza developed well in loose soil, that also effectively used as food coloring, spice, starch sources and dye in cosmetics (Sok-Lai Hong, 2014). Rhizome of temulawak has its own essential oil containing volatile aromatic compounds of C. xanthorrhiza. Essential oil or known as volatile oil is the oil extracted from 
C. xanthorrhiza which have the essence of this plant's fragrance. The essential oils of the rhizome temulawak reported has antibacterial activity (Mary et al. 2012).

C. xanthorrhiza contained active compounds that reported has activity as antitumor like $\alpha$-curcumene, ar-turmerone, and xanthorrhizol (Itokawa et al 1985). Its essential oils also have potential to be developed as sources of antimicrobial, which inhibit bacterial growth making it good remedies for several infections (Mohamed Farag and Mohamed 2015)

Beside the rhizome part, the leaves and flower bract of temulawak essential oils also had been reported has activity as antimicrobe (Batubara et al. 2015, Batubara et al. 2016). On the other hand, the distillation process need time, and different distillation time will produce essential oils with different yields and components. So, the sole purpose of this study is to determine the antibacterial activity of $C$ xanthorrhiza leaves and rhizomes essential oil with different distillation time of 2 hours, 4 hours and 6 hours against human pathogenic bacteria which are Escherichia coli and Staphylococcus aureus.

\section{METHOD}

This research was conducted at Analytical Laboratory in Chemistry Department and Tropical Biopharmaca Research Center, Bogor Agricultural University in Bogor, Indonesia from March to June of 2018. Materials used were fresh leaves and rhizomes of $C$. xanthorrhiza, bacteria of Escherichia coli and Staphylococcus aureus, and liquid agar medium. Materials for separation of compounds including silica gel coated on aluminum sheet, TLC $G_{50} F_{254}$ and instrumentation of CAMAG Reprostar 3 with digital camera.

\section{Distillation}

The essential oil of temulawak leaves $(5.0 \mathrm{~kg})$ was separated by steam distillation method. Leaves sample was firstly cut into medium pieces and weighed to fit with $5 \mathrm{~L}$ of distilled water. Extraction of aromatic compounds tooks around 6 hours, the essential oil were taken 3 times every 2 two hours and collected in the vials. Followed by the rhizomes $(4.8 \mathrm{~kg})$ was extracted using the same method as before. These vials were label as D1 (first 2 h), D2 (2-4h), D3 (4-6h) for leaves samples and R1 (first 2h), R2 (2-4h), R3 (4-6h) for rhizomes samples. The essentials oils yield then was determined by comparing the volume and weight of oils produced against the weight of original materials.

\section{Separation with Thin Layer Chromatography and Bioautography Contact}

The essential oils samples were diluted with methanol to $2 \%$ for analysis. The chromatographic was performed using TLC $\mathrm{G}_{50} \mathrm{~F}_{254}$ aluminum sheet $(10 \mathrm{~cm} \times$ $10 \mathrm{~cm})$ and $n$-hexane: toluene: dichloromethane (1:8:1) as the mobile phase. The aluminum sheet was put into a chromatographic chamber which had been saturated for 30 minutes with the mobile phase. After elution, the dried chromatogram was detected by UV $254 \mathrm{~nm}$ and $366 \mathrm{~nm}$. The spot intensity was determined by Image $\mathrm{J}$ to find the tendency of each Rf on different distillation time.

The other dried chromatogram with the same process, left for 1 hour in a sterile dish facing upwards. The liquid agar medium which had been inoculated with $S$. aureus and $E$. coli culture was then poured onto the chromatogram. After compacting, the petri dish was incubated at $37^{\circ} \mathrm{C}$ for 24 hours (Hamburger \& Cordell, 1987). The clear zone on the spots means the spots is active as antimicrobe.

\section{RESULT AND DISCUSSION \\ Distillation yields}

Based on the result obtained, the essential oil for D1 yielded the highest content of oil which was $2.5353 \mathrm{~g}$ and the lowest yield of $0.4706 \mathrm{~g}$ for D3 from $5 \mathrm{~kg}$ leaves. Meanwhile, for rhizome, the highest yield of essential oil was R1 and the lowest yield was R3 with $1.0464 \mathrm{~g}$ and $0.6726 \mathrm{~g}$ respectively from $4,8 \mathrm{~kg}$ rhizome. The products of $C$. xanthorrhiza essential oil obtained by steam distillation methods for both leaves and rhizomes samples was shown in Table 1 , and the picture of the oils is shown in Figure 1. Increasing the time for distillation could increase the oil produced, but the increasing rate is become slower. The first two hours distillation gave the highest yields and the last two hours yields is the lowest.

\section{Thin Layer Chromatogram Profile}

The component of the essential oils produced then determined by thin layer chromatography. The chromatogram is shown in Figure 2. The component on the essential oils (leaves and rhizome) for the first $2 \mathrm{~h}$ distillation time is less than others, based on the spot intensity. It can be shown based on the area on spots in

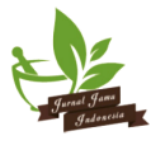




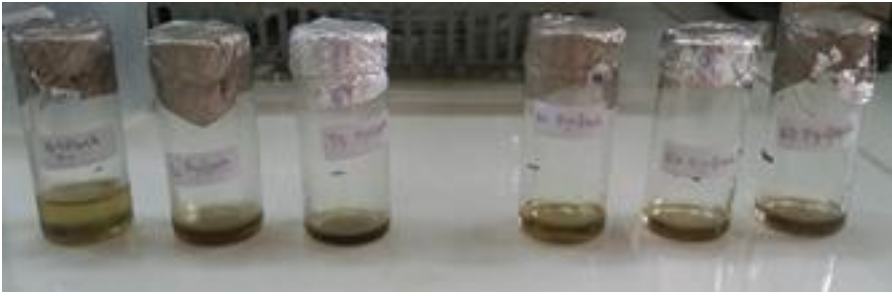

Figure 1. Essentials oils of temulawak from left to right

$$
\text { D1, D2, D3, R1, R2, R3 }
$$

chromatogram. The area of each spots is increasing with the distillation time increase. The number of spots for leaves essential oils in $254 \mathrm{~nm}$ is 6 spots while in $366 \mathrm{~nm}$ only 4 spots. The number of spots for the rhizome essential oils is 5 spots while in $366 \mathrm{~nm}$ is the same. This phenomenon indicate that the essential oil of the leaves and rhizome is little bit different, especially the spot with $\mathrm{Rf} 0.3$ which only found in the leaves not in rhizome essential oils. The same $\mathrm{Rf}$ value of the spot between leaves and rhizome essential oils indicate the same components.

The spot area of each $\mathrm{Rf}$ from different distillation time then determined to find the trend on distillation process. The results are shown in Figure 3. In leaves essential oils, component with $\mathrm{Rf} 0.90,0.55$, and 0.30 are increase by increasing the distillation time, while spot with Rf 0.35 slightly decrease. In rhizome essential oils, $\mathrm{Rf} 0.90,0.55$, and 0.50 are increase by increasing the distillation time, while spot with $\mathrm{Rf} 0.35$ and 0.10 are decrease.

\section{Antibacterial activity}

C. xanthorrhiza essential oil inhibits both of the bacteria tested. Bacterial inhibition zone formed by Escherichia coli and Staphylococcus aureus for leaves and rhizomes samples were shown in Figure 4.

Table 1. Essential oils yield of $C$. xanthorrhiza by distillation method.

\begin{tabular}{lllccc}
\hline No & Part of plant & Distillation time (h) & Sample name & \multicolumn{2}{c}{ Yield (\%) wet basis } \\
\cline { 4 - 5 } & & & w/w & v/w \\
\hline 1 & Leaves & $0-2$ & D1 & 0.051 & 0.058 \\
2 & Leaves & $2-4$ & D2 & 0.014 & 0.020 \\
3 & Leaves & $4-6$ & D3 & 0.009 & 0.018 \\
4 & Rhizome & $0-2$ & R1 & 0.022 & 0.025 \\
5 & Rhizome & $2-4$ & R2 & 0.018 & 0.023 \\
6 & Rhizome & $4-6$ & R3 & 0.014 & 0.021 \\
\hline
\end{tabular}
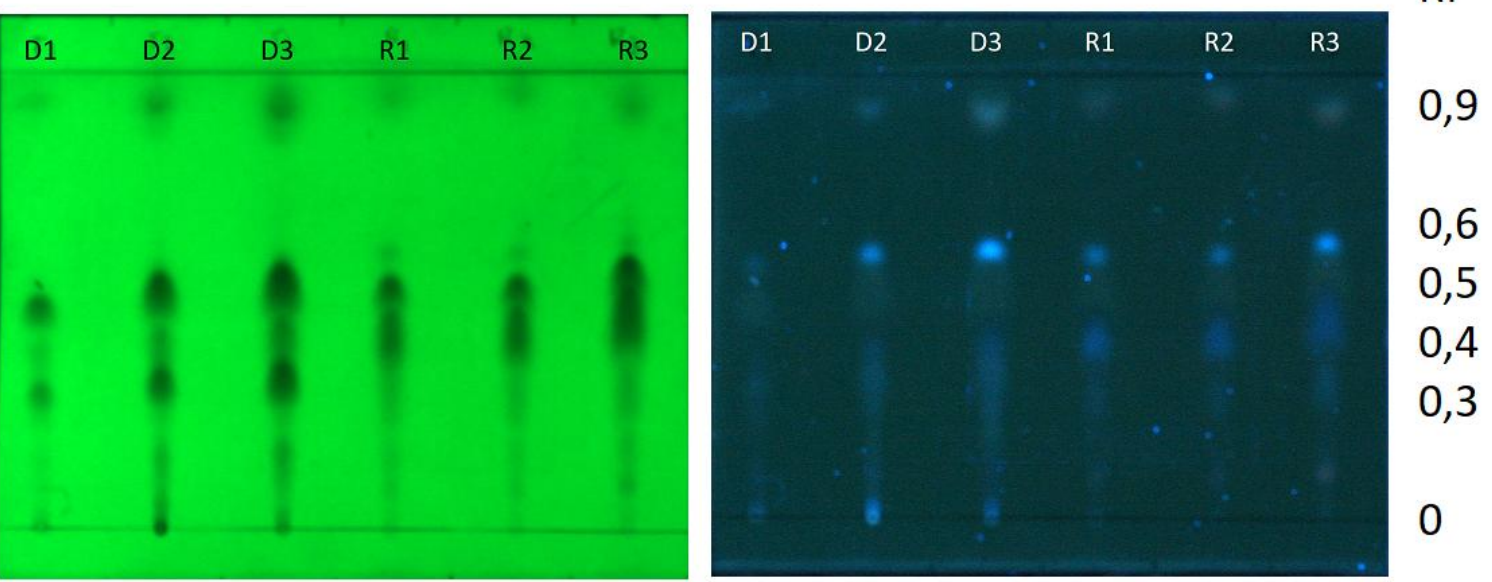

Figure 2. Chromatogram of $C$. xanthorrhiza essential oil D1 (leaves, first 2h), D2 (leaves 2-4h), D3 (leaves 4-6h), R1 (rhizome, first 2h), R2 (rhizome, 2-4h), R3 (rhizome 4-6h) using $n$-hexane: toluene: dichloromethane (1:8:1) with Rf values tested under UV $254 \mathrm{~nm}$ (left) and $366 \mathrm{~nm}$ (right). 
Inhibitory activity against bacteria was measured based on clear zone form on band on the chromatogram plate. The result shows the band on leaves essential oil with $\mathrm{Rf}$ of 0.3 till 0.92 were active to inhibit $E$ coli and $S$ aureus growth. On the other hand, the band for rhizome essential oil inhibit both bacteria were $\mathrm{Rf}$ of 0.47 and 0.92 . The band with $\mathrm{Rf}$ of 0.47 and 0.92 were appeared in leaves and rhizome essential oils. These two band probably has the same chemical component. It can be concluded that $C$. xanthorrhiza essential oils potent to inhibit the growth of bacteria. As time increased, the inhibitory zone became clearer thus indicates the antibacterial activity. Among active compounds in rhizomes of $C$. xanthorrhiza was xanthorrhizol that extracted from essential oil which possessed as antibacterial activity (Oon et al. 2015).

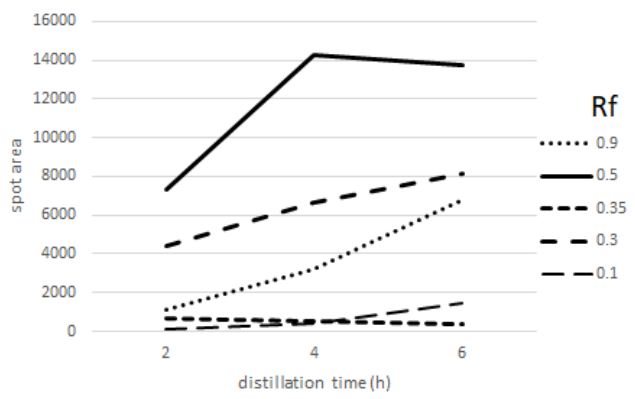

(a)

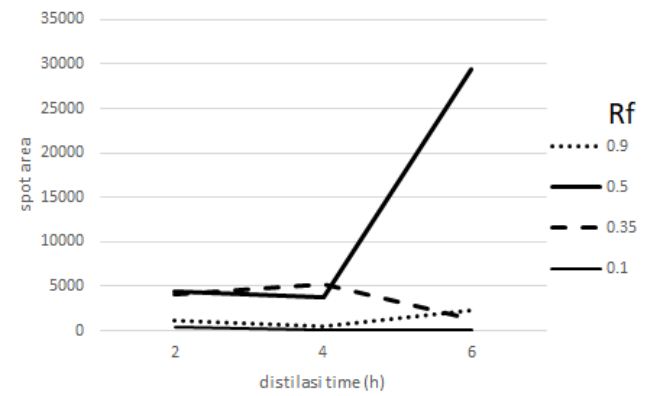

(c)

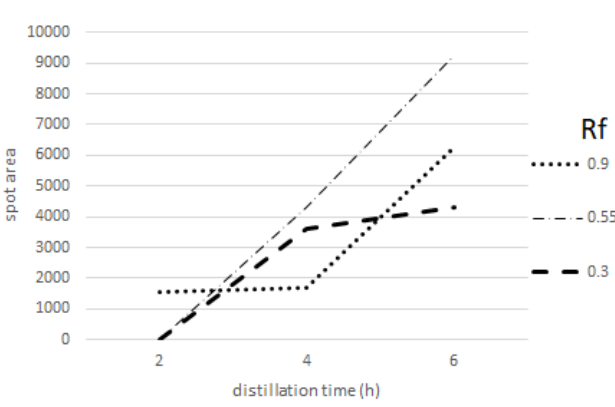

(b)

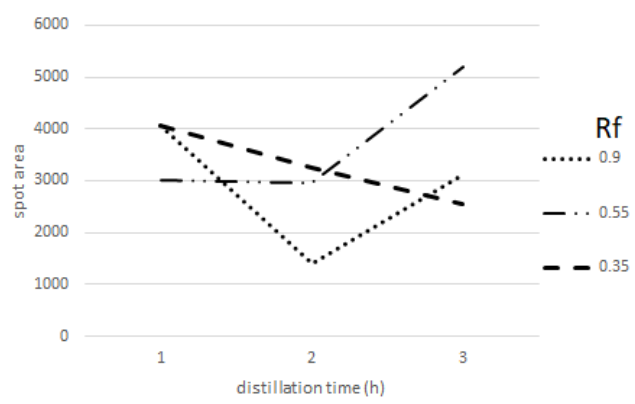

(d)

Figure 3. The correlation of spot area and distillation time on each $\mathrm{Rf}$ of leaves essential oil at $254 \mathrm{~nm}$ (a), 366 $\mathrm{nm}$ (b) and rhizome essential oil at $254 \mathrm{~nm}$ (c) and $366 \mathrm{~nm}$ (d)

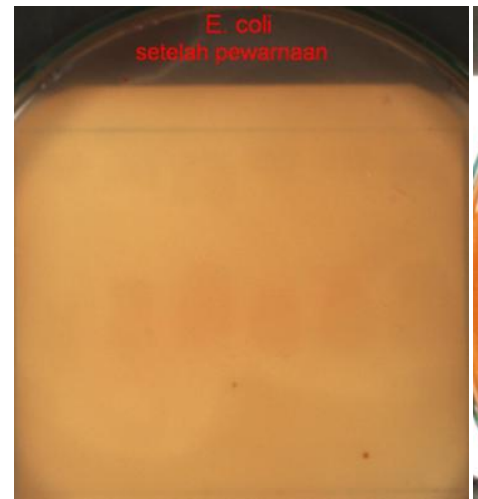

(a)

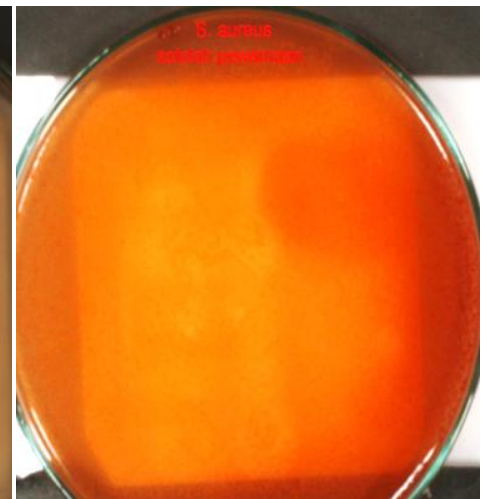

(b)

Figure 4. Antibacterial activity of $C$. xanthorrhiza essential oils against bacteria of (a) Escherichia coli and (b) Staphylococcus aureus 


\section{CONCLUSION}

Curcuma xanthorrhiza leaves and rhizome essential oil have the potential of antibacterial activity towards Escherichia coli and Staphylococcus aureus. Chromatogram of $C$. xanthorrhiza essential oils shown the most significance inhibitory zone against $E$. coli and S. aureus at $\mathrm{Rf} 0.47$ and 0.92 , which active as antibacterial spots.

\section{REFERENCES}

Batubara I, Julita I, Darusman LK, Muddathir AM, Mitsunaga T. 2015. Flower bracts of temulawak (Curcuma xanthorrhiza) for skin care: anti-acne and whitening agents. Procedia chemistry 14:216-224

Batubara I, Wahyuni WT, Sutanta M. 2016. Antibacterial activity of zingiberaceae essential oils against Streptococcus mutans and teeth biofilm degradation. IJPBS. 7(4): p111-116

Hamburger MO, \& Cordell GA. 1987. A direct bioautographic TLC assay for compounds possessing antibacterial activity. Journal of Natural Products. 50(1): 19-22.

Itokawa H, Hirayama F, Funakoshi K, Takeya K. 1985. Studies on the antitumor bisabolane sesquiterpenoids isolated from Curcuma xanthorrhiza. Chemical and Pharmaceutical Bulletin. 33(8): 3488-3492

Kalor H, \& Atun S. 2017. The Antibacterial Activity of Curcuma xanthorrhiza Extract Against Escherichia coli ATCC 11229 and Staphylococcus aureus ATCC 25923. Jurnal Penelitian Saintek. 22(2): 140-147.

Mary HPA, Susheela GK, Jayasree S, Nizzy AM, Rajagopal B, Jeeva S. 2012. Phytochemical characterization and antimicrobial activity of Curcuma xanthorrhiza Roxb. Asian Pacific Journal of Tropical Biomedicine. 2(2) supplement S637-S640
Farag $\mathrm{M}$, Foud I, Ahmed WJ, Mohamed MS, Mohammed MS. 2015. The Role of Natural Products In Drug Discovery And Development. World Journal of Pharmaceutical Research, 4(3).

Oon SF, Nallappan M, Tee TT, Shohaimi S, Kassim NK, Sa'ariwijaya MSF, Cheah YH. 2015. Xanthorrhizol: a review of its pharmacological activities and anticancer properties. Cancer Cell International. 15(1), 100. doi:10.1186/s12935-015-0255-4

Ozaki Y. 1990. Anti-inflammatory effect of Curcuma xanthorrhiza ROXB and its active principles. Chemical and Pharmaceutical Bulletin. 38(4):10451048

Rukayadi Y, Hwang JK. 2007. In vitro antimycotic activity of xanthorrhizol isolated from Curcuma xanthorrhiza Roxb against opportunistic filamentous fungi. Phytotherapy Research. 21(5):434-438.

Sok-Lai Hong G-SL, Rahman SNSA, Hamdi OAA, Awang K, Nugroho NA, Malek SN. 2014. Essential oil content of the rhizome of Curcuma purpurascens Bl.(Temu Tis) and its antiproliferative effect on selected human carcinoma cell lines. The Scientific World Journal. 2014(3).

Sylvester WS, Son R, Lew KF, Rukayadi Y. 2015. Antibacterial activity of Java turmeric (Curcuma xanthorrhiza Roxb) extract against Klebsiella pneumoniae isolated from several vegetables. International Food Research Journal. 22(5):17701776

Yasni S, Imaizumi K, Sin K, Sugano M, Monaka G, Sidik. 1994. Identification of an active principle in essential oils and hexane soluble fraction of Curcuma xanthorrhiza Roxb showing triglyceride lowering action in rats. Food and Chemical Toxicology. 32:273-378

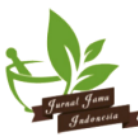

